\title{
Karl Jaspers' General Psychopathology (Allgemeine Psychopathologie) and Its Implication for the Current Psychiatry
}

\author{
Seon-Cheol Park $\bowtie$ \\ Department of Psychiatry, Inje University Haeundae Paik Hospital, Busan, Republic of Korea
}

Karl Jaspers is a psychiatrist, philosopher, and humanist. In 1913, he published the General Psychopathology (GP; Allgemeine Psychopathologie), the first edition. Despite the passage of one hundred years after the GP was published, GP still has a potential value to present a phenomenological and comprehensive viewpoint for psychiatry to overcome Kraepelinian -biological absolutism. The philosophical backgrounds of a Jaspersian phenomenological sense have been related to both the transcendence and the immanence roots. Partly under the influence of a Husserlian distinction between the natural and phenomenological attitudes, a rigid distinction between explanation and understanding has been proposed as the proper epistemological method in Jaspers' GP. Further, the fact that a distinction between process and development has been presented as the psychical phenomenon is understandable. The integrated and comprehensive viewpoint establishment for the state of "Babylonian confusion of tongues" in German psychiatry as well as the newly initiating phenomenological trend in psychiatry have been the legacies of Jaspers' GP. Moreover, the common theoretical backgrounds may be shared by the Jaspersian sense and humanitarian approaches in Korean psychiatry. Also, the Jaspersian sense may help the current molecular psychiatry to have a chance to overcome its solipsism and limitations.

Psychiatry Investig 2019;16(2):99-108

Key Words Karl Jaspers, General Psychopathology, Transcendence, Immanence, Korean psychiatry.

\section{INTRODUCTION}

In 2013, from the viewpoint of psychopathology, two major and opposite events happened. One was the publication of the Diagnostic and Statistical Manual of Mental Disorders, 5th edition (DSM-5) by the American Psychiatric Association (APA) and the other was the 100th anniversary of the first publication of Karl Jaspers' General Psychopathology (GP; Allgemeine Psychopathologie), first edition. To overcome arbitrariness and indistinctness of the DSM-I (1952) and DSM-II (1968) based on the psychoanalytic backgrounds, the empirical trends in a "Kraepelinian world" influenced the DSM-III (1980), DSMIV (1994), and DSM-5 (2013). ${ }^{1-7}$ Because Jaspers had proposed the flexible psychiatric taxonomy against the Kraepelinian biological absolutism (Table 1), the DSM-III was denoted as the "anti-Jaspersian" diagnostic scheme. ${ }^{8}$ Despite the newly an-

Received: October 5, 2018 Revised: December 5, 2018

Accepted: December 19, 2018

$\triangle$ Correspondence: Seon-Cheol Park, MD, PhD

Department of Psychiatry, Inje University Haeundae Paik Hospital, 875 Haeundaero, Haeundae-gu, Busan 48108, Republic of Korea

Tel: +82-51-797-330, Fax: +82-51-797-0298

E-mail: cogito-ergo-sum@hanmail.net

(c) This is an Open Access article distributed under the terms of the Creative Commons Attribution Non-Commercial License (https://creativecommons.org/licenses/bync/4.0) which permits unrestricted non-commercial use, distribution, and reproduction in any medium, provided the original work is properly cited. nexed utilization of dimensional model, the DSM-5 has continually exploited a Kraepelinian nosological model that all mental illnesses can be categorically defined as a "real, recognizable, unitary, and stable (RRUS)" object. ${ }^{8-11}$ However, with the continual expanding of empirical trends in the DSM, the phenomenological gestalt has gradually disappeared, and only the concept for chronic paranoid psychosis has remained in the diagnostic criteria for schizophrenia. ${ }^{12}$ Hence, the decline of person-centered psychopathology due to fitting mental illness to traditional medical model was criticized as the unintended consequence of the DSM. Also, the emphasis on the DSM rather than the complex lessons from the great psychopathologists of the past was named as "the death of phenomenology in the United States" by Nancy Andreasen. ${ }^{13}$ Most of all, the enrichment of phenomenological psychopathology was suggested to be the most important achievement of Karl Jaspers' GP. Thus, despite the passage of 100 years after its first edition publication, $G P$ has a virtue to describe, define, and classify psychic phenomena from the perspective of phenomenology and provide comprehensive knowledge and methods for evaluating and understanding mental symptoms without adherence to specific doctrines. Also, the GP has been expected to have the potential to replenish the lack of philosophy in the current operational classification of mental illness 
Table 1. Karl Jaspers' classification of psychiatric disorders

\begin{tabular}{|c|c|c|}
\hline Group I & Group II & Group III \\
\hline $\begin{array}{l}\text { Known somatic illnesses with } \\
\text { psychic disturbances }\end{array}$ & The three major psychoses & Personality disorders \\
\hline 1. Cerebral illnesses & 1. Genuine epilepsy & $\begin{array}{l}\text { 1. Isolated abnormal reactions that do not arise on the } \\
\text { basis of illnesses belonging to Group I and II }\end{array}$ \\
\hline 2. Systemic diseases with symptomatic psychoses & 2. Schizophrenia & 2. Neuroses and neurotic syndromes \\
\hline 3. Poisons & 3. Manic-depressive illnesses & 3. Abnormal personalities and their development \\
\hline
\end{tabular}

and the limitations of natural-scientific approaches in contemporary psychiatry. ${ }^{14-23}$

Thus, Karl Jaspers' GP, its introduction, philosophical background, the new introduction of phenomenology into psychopathology, influence on Korean psychiatry, and its implications for current psychiatry are reviewed and discussed in this paper.

\section{KARL JASPERS' BIOGRAPHY AND GENERAL PSYCHOPATHOLOGY}

Karl Jaspers (1883-1969) was a psychopathologist and existential philosopher in Germany. Despite his entrance into the law school at Heidelberg University in 1901, Jaspers changed his major to medicine. For his registrar period at Heidelberg Clinic from 1909 to 1915, Jaspers had active discussions with great clinicians including Franz Nissl (1860-1919), Hans W. Gruhle (1880-1958), Otto Ranke (1899-1959), and Willy Mayer Gross (1889-1961). Jaspers recalled that the GP was written thanks to the creative thinking that originated from Heidelberg University Hospital. Jaspers published the Homesickness and Crime (Heimweh und Verbrechen) as a doctoral thesis in 1908. Since a publisher, Ferdinand Springer junior (1881-1965), requested him to write a textbook for psychopathology in 1911, Jaspers published the first edition of the GP in 1913. He made a statement that psychiatry was neither the applications of neuroanatomy, neurophysiology, or clinical psychology nor a simple collection of clinical cases. Further, he accentuated that psychiatry should have its own academic system, method, and that psychopathology should be established as an academic discipline from the perspective of phenomenology. Nissl's appraisement for the GP was as follows: "Great, Jaspers is much better than Kraepelin." Jaspers became a guest professor in the department of psychology at Heidelberg University in 1916. Owing to the shift from psychiatry to philosophy in terms of his academic viewpoints, despite the opposition of Heinrich Richert (1863-1936), he became a full professor in department of philosophy at Heidelberg University in 1922 . However, because he refused to divorce his Jewish wife despite the enforce- ment of Nazis, he was deprived of his professorship by the Nazis in 1937. After the fall of Nazis, his professorship in Heidelberg University was restored in 1945 . He then moved to department of philosophy at Basel University in Switzerland for the purpose of philosophical realization of the transcendence of nationalism in 1948 and retired at Basel University in 1961. For his publication of the Atomic Bomb and Future of Humans (Die Atombombe und die Zukunft der Menschen, 1958), he won the Nobel Peace Prize in 1963. ${ }^{24-33}$ Hence, according to the proposal of a Japanese scholar to study Jaspers' biography, the advances in the academic works of Jaspers can be divided into three discrete phases including psychiatry (1909-1919), philosophy (I) (1920-1932), and philosophy (II) (1933-1969). The distinctions between the psychiatry and philosophy (I) phases and between philosophy (I) and philosophy (II) are based on publications of the Psychology of Worldviews (Psychologie der Weltanschauungen, 1919) and the Philosophy (Philosophie, 1932), respectively (Table 2).$^{34}$ More specifically, the Psychology of Worldviews handled and discussed the limit situation, multidimensionality of time, movement of freedom, self-productivity of existence and nihilism from the viewpoint of psychology and the Philosophy proposed the appearance of eternal philosophy to overcome self-closure aspect of the present age and essence of existential philosophy from the comprehensive facts.

The GP was additionally revised eight times after the publication of its first edition even after his academic field changed from psychiatry to philosophy. Moreover, the final (ninth) edition was published in 1973 after his death in 1969. It was known that new research findings presented from a literature review were continuously added into the GP. Hence, as the number of editions increased, the number of pages for the GP continually increased. During his time at the Heidelberg school, Jaspers mainly focused on the phenomenological-anthropological approaches to psychopathology based on the applications of philosophical methods. Thus, the trajectory for the GP revisions and contemporary main publications of the Heidelberg school is additionally presented in Table $2 .^{31-33}$ Since A. 
Table 2. Karl Jaspers' General Psychopathology (Allgemeine Psychopathologie) revisions and Heidelberg school's main publications

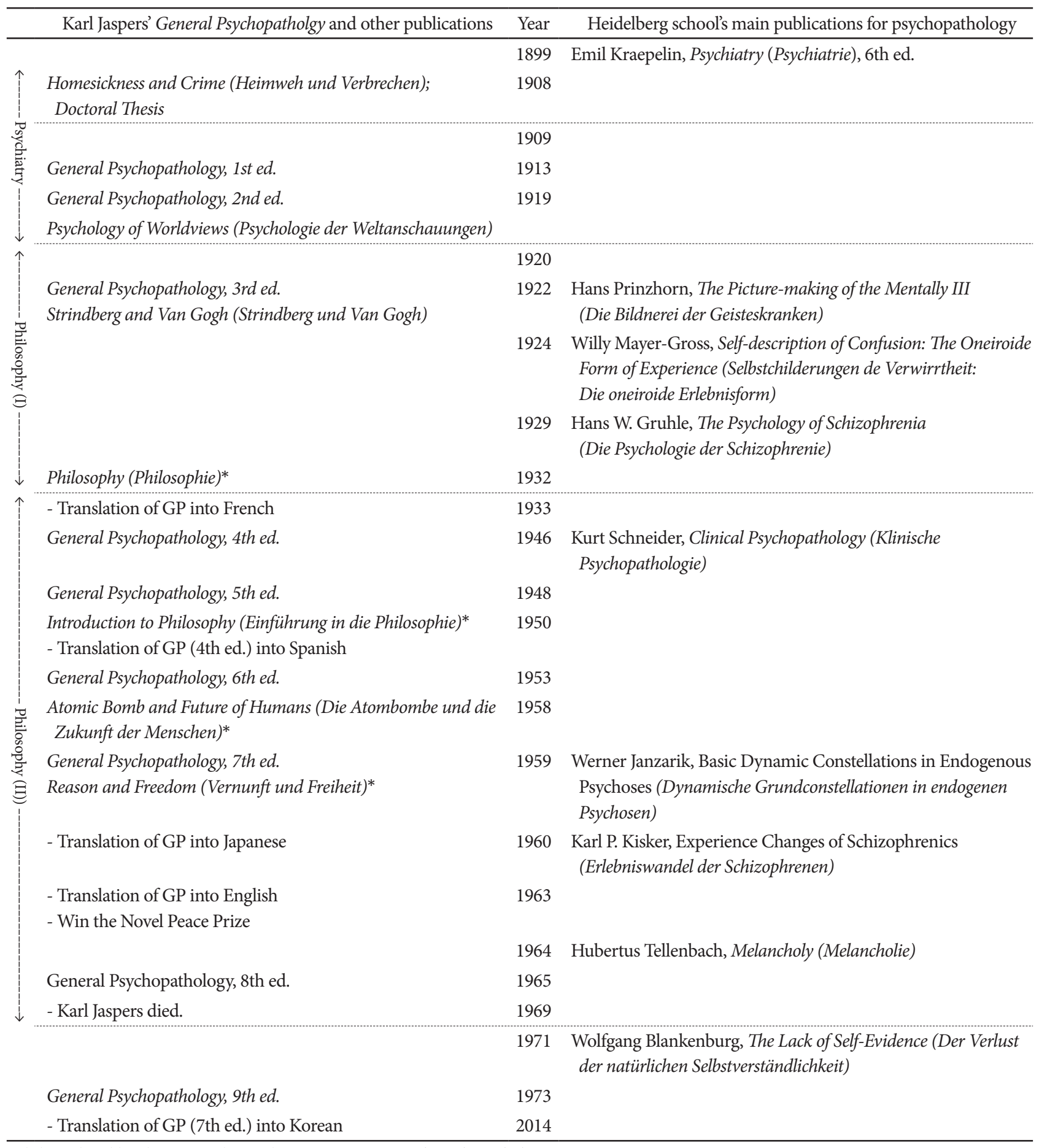

*philosophical books written by Karl Jaspers. GP: General Psychopathology

Kastler and J. Mendousse translated the GP into French with assistance from Sartre and Nizan in 1933, the GP was translated into a foreign language for the first time. Under the influences of the GP on French psychopathology at that time, Jacques Lacan's essay on the Paranoid Psychosis in Relation to Person- ality (de la psychose paranoique dans ses rapports avec la personalite) was published. The GP was additionally translated into Spanish (1950) and Japanese (1960). ${ }^{34-37}$ Also, John Hoenig finished the translation of GP in English (1963). In the process of the English translation, there was an interesting ep- 
isode as follows: Stengel, a leading psychoanalyst, asked Hoenig "why do you waste your time with this Imperial Psychiatry?" However, Mayer-Gross answered Stengel that "there is nothing imperial here, it is just the most important book in psychiatry."38

Thanks to Bou Yong Rhi, a part of the GP was translated into Korean and introduced to Korean psychiatry in $1974 .{ }^{39}$ Also, the full translation of the GP into Korean was first conducted under the leadership of Ji Young Song and supported by the translation fund of National Research Foundation in Korea. The Korean translation started in 2008 and ended in 2013, which was one hundred years since the GP's first edition was published. GP was translated and annotated by two Korean psychiatrists, two Korean philosophers, and four Korean scholars of German literature. Due to Jaspers' unique style, difficult expression and uneasy conceptualization, the Korean translation of $G P$ was likened to a triathlon in terms of translation by the translators themselves. Additionally, the translation and annotation were supervised by six Korean psychiatrists. Finally, the Korean translation of GP was divided into four volumes and published in 2014. The images of Max Weber (1864-1920), Immanuel Kant (1724-1804), Friedrich Nietzsche (1844-1900) and Søren Kierkegaard (1813-1855) as well as that of Jaspers were serially printed in the volume covers of its Korean translation (Figure 1), since Jaspers' GP was deeply interested in philosophical thoughts and influenced by ideas of the four great philosophers. ${ }^{40}$

\section{PHILOSOPHICAL BACKDROPS OF KARL JASPERS' GENERAL PSYCHXOPATHOLOGY}

As shown in Figure 2, the philosophical thoughts of Karl
Jaspers' GP could be rooted from the two theoretical backgrounds of transcendence and immanence, although there is substantial controversy. ${ }^{41-43}$ Most of all, Karl Jaspers was under the influence of Wilhelm Dilthey's cultural science and Edmund Husserl's phenomenology. Hence, the phenomenological operations could be introduced into psychopathology and an individual's own whole image and subjective experience might be emphasized. Dilthey proposed an idea of the unity of life' that our experience of continuity having no caesurae in the Introduction to the Humanities (Eineitung in die Geisteswissenshaften). With regard to philosophy of life (Lebensphilosophie), it was stated that "life is a unity, a form of becoming, a variation around a theme or a set of themes." In accordance with a Diltheyan sense, Jaspers could be regarded as a thinker of "continuum" in terms of the interrogation of the unity of constituting life rather than as a multifaceted expression. In a Diltheyan sense, it was declared that "nature ought to be explained and life ought to be understood." Also, Dilthey made an observation that historians could simply understand those who made history because they were men who in their turn acted within history and made history. In the GP, consistent with a Diltheyan sense, the typical and rigorous distinction between explanation (Erklären) and understanding (Verstehen) were considered to be of central relevance (Table 1). ${ }^{30,44-48} \mathrm{Ex}$ planation denotes that the examiner explain causality through a series of courses including individuating heterogenous elements in the examined phenomena, interweaving those elements in discrete temporal series, and making one the cause of the others. Understanding denotes that the examiner understands from within, having direct access to that phenomenon that we are. An ultimate backdrop of a Diltheyan sense was corresponded to a Kantian view and confirmed by Husserl's Crisis of the European Sciences (Krisis der europaeischen
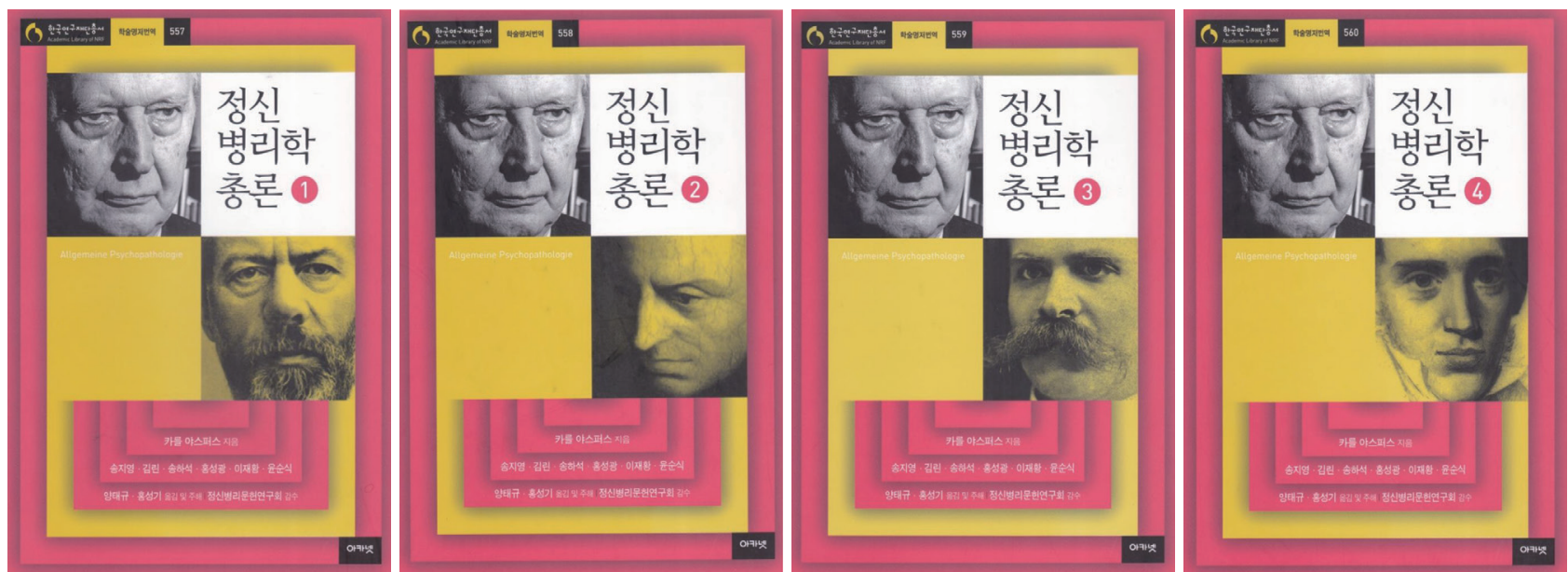

Figure 1. The images of Max Weber, Immanuel Kant, Friedrich Nietzsche and Søren Kierkegaard (from left to right) in volume covers of the Korean translation of General Psychopathology. Adapted from Song et al. translation. General Psychopathology 1, 2, 3, and 4. Seoul: Acanet; 2014. 


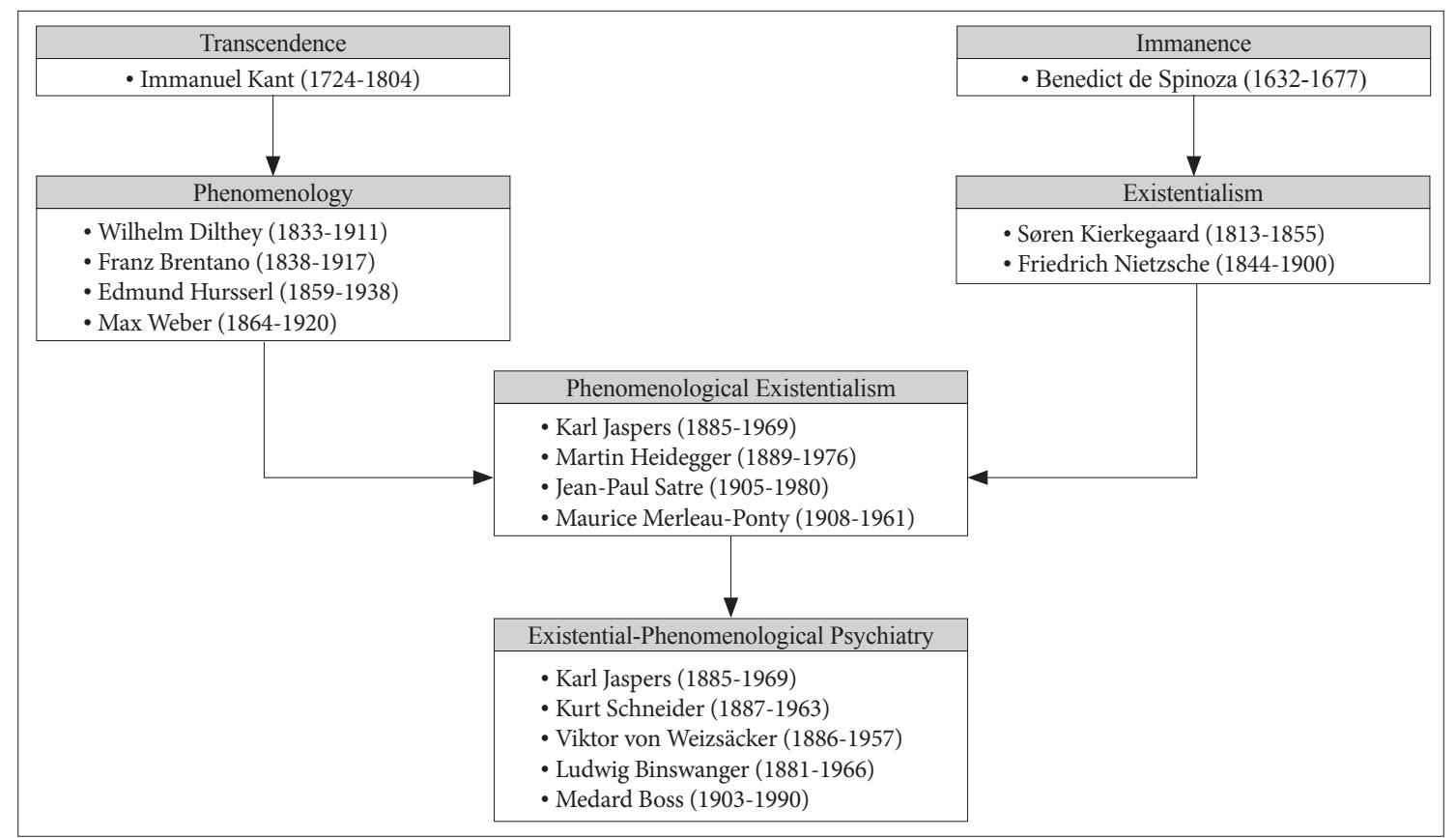

Figure 2. Karl Jaspers' phenomenology and chronology of the trends in phenomenological psychiatry.

Wissenschaften) as follows. In a Husserlian sense, there were by no means sciences of nature and sciences of spirit. There were only sciences of spirit, which investigate spirit either in a direct and humanistic method or in an indirect and natural scientific method. ${ }^{41,43}$

With reference to typicality, in a Husserlian sense, in the GP, it was insisted that the psychiatrist ought to identify a typicality for each form of psychopathological life in a Jaspersian sense. Thus, the relationship between psychosis and life context could be studied by investigating a series of typical connections at the level of understandability in a Diltheyan sense as well as at the level of statistical recurrence. Based on certain lines of possible congruence, synchronicity, and diachronicity, the purposes of a Jaspersian view could be defined as the establishment of a unity out of multiplicity and the grouping of fragments and innumerable expressions of psychopathological experience. Consequently, the identifying of typicality in a Jaspersian view meant to find a sort of eidetic and genetic law out of the experiences. However, it was pointed out that Jaspers' using the term phenomenology as a synonym for static understanding was considerably different from the usage of phenomenology in a Husserlian sense. Hence, Jaspersian phenomenology could be partly influenced by Husserlian and Diltheyan views and affirmed as a form of descriptive psychopathology which is different from Husserlian phenomenology. ${ }^{41,43}$

Also, Jaspers was influenced by Max Weber's idea which enables us to identify one category by looking at the phenomenon as a whole and seize the irrationality beyond productive rationality. Weber's ideal type (Idealtypus) concept denoted a stable and consistent phenomenon with univocal and verifiable features in reaching a specific but rigorous objectivity from the perspective of sociology. By Jaspers, the ideal type concept was first referred in the Causal and Understandable Relationships (Kausale und verständliche Zusammenhänge). Under the potential influences of Weber's essay on the Objectivity of Sociological and Socio-Political Knowledge (Die Objektivität sozialwissenschafticher und sozialpolitiker Erkenntnis), the operations which the historian or sociologist performs on the materials they work with could be used by phenomenological psychopathology. Thus, insight, empathy, and immediate understanding were considered useful psychiatric methods to reveal the contents of a patient's experience and subsequently enable an exert series of phenomenological operations including confrontations, critical analysis, and comparative elaborations. ${ }^{42,43}$

Along with a philosophy of life, a Nietzschean view constituted the other seminal backdrop for Jaspers' GP. Thus, in the $G P$, Jaspers stated that man is a sick being because of his own incompleteness. Also, human life was regarded as the inhabitant of an inescapable form of danger, which was at the same time his creative overture and the constant possibility of failure and misdirection. Through turning psychopathology into anthropology, a Niezschean view was profitably used by the Kierkegaardian eye of Jaspers as follows: Jaspersian psychopathology was established on the premise that philosophy would guide the thought of psychiatry and defines that madness was a pathology of liberty since it embarrasses freedom itself and it locked the subject into a repetition without variation. ${ }^{41,43}$ 


\section{INITIATING A NEW PHENOMENOLOGICAL TREND IN PSYCHIATRY}

Before publication of Jaspers' $G P$, the brain mythology was firstly proposed by Wilhelm von Grisinger (1817-1868) and was quite popular in the realm of psychopathology. At that time, to distinguish and classify the psychic phenomenon properly was the aim of scientific investigation in psychiatry. Emil Kraepelin (1856-1927) was the first to propose the systemic and critical psychiatric classification for a distinction between dementia praecox and manic-depressive psychosis from the viewpoint of not the causal explanation but the descriptive observation for prognosis. ${ }^{8-11}$ Whereas Kraepelin was concerned on the subjective features of psychic symptoms under the influence of Wilhelm Wundt (1832-1912), his primary focus was on identifying the objective features of the symptoms. Jaspers estimated Kraepelin's attitude for psychopathology, in $G P$, as follows:

"But Kraepelin's basic conceptual world remained a somatic one which in the company of the majority of doctors he held as the only important one for medicine, not only as matter of preference but in an absolute sense. The psychological discussions in his Textbook are brilliant in parts and he succeeded with them as it were unwittingly. He himself regarded them as temporary stopgaps until experiment, microscope, and testtube permitted objective investigation (Jaspers)."

In 1900 and 1901, in a warning against the overestimation of the investigation of the central nervous system, the priority of inner experience over material factors was stressed by Wilhelm Weygandt (1870-1939). In 1912, by the initiation to publish the Journal of Pathopsychology (Zeitschrift für Pathopsychologie), Wilhelm Sprecht, Henri Bergson, Hugo Münsterberg, and Oswald Külpe came together to reform psychopathology along the lines of descriptive psychopathology. The first volume was represented by Max Scheler, and the second was contributed by Jaspers. Based on Husserl's distinction between the natural and the phenomenological attitudes, Sprecht supported that a phenomenology of the psychic phenomenon should be followed by experimental psychology. Further, since Spreht regarded psychoanalysis not as a brain-centered approach but as an arbitrary construction of its fundamental concepts, he was unable to accept psychoanalysis eventually. ${ }^{50,51}$

Before and after World War I, Griesinger, Meynert, and Wernicke achieved the remarkable findings for the relationship between mental illness and brain, Nissl and Alzheimer introduced a new staining method to see the tissues of central nervous system, Kraepelin newly classified the psychoses, and Bleuler established a new theory for conceptualizing schizo- phrenia. Since the theoretical confusions resulted from the heterogenous findings which had originated from diverse backgrounds including genetics, neuroanatomy, neurophysiology, and clinical psychology, German psychiatry was in place of "Babylonian confusion of tongues" at that time. In a Jaspersian sense, psychiatry should neither be the mere application of neuroanatomy, neurophysiology, or clinical psychology nor the simple recruitment or sorting of clinical cases, but rather the field "encompassing" all the theoretical backgrounds. Based on a clear methodology distinguishing the major methods employed, Jaspers mainly aimed at a synthesis of all the insights in the psychiatric fields. ${ }^{15-23,30,45-48}$ With regard to the place of Karl Jaspers' GP of 1913 in phenomenological trend, Herbert Spiegelberg stipulated that the GP should be the "first major landmark on the way to a phenomenological psychopathology in touch with phenomenological philosophy." ${ }^{22,53}$ Jaspers explicated the term phenomenology as follows:

"The term phenomenology was used by Hegel for the whole field of mental phenomena as revealed in consciousness, history, and conceptual thought. We use it only for the much narrower field of individual psychic experience. Husserl used the term initially in the sense of 'descriptive psychology' in connection with the phenomenon of consciousness; in this sense it holds for our investigations also, but later on he used it in the sense of 'the appearance of things (Wesensschau)' which is not a term we use in this book. Phenomenology is for us purely an empirical method of enquiry maintained solely by the fact of patients' communications. It is obvious that in these psychological investigations descriptive efforts are quite different from those in the representation of it (Jaspers). ${ }^{34}$

Thus, in a Jaspersian sense, the task of the phenomenological trend in psychiatry was defined as presentification (Vergegenwätigung), demarcation (Begrenzung), and description (Beschreibung). In spite of its connection with the intuitive fulfillment of intentions in free imagination, presentification is not a primary component of the Husserlian phenomenological method. Thus, it was considered that presentification was involved in not a perceptual experience but an imaginative procedure as follows:

"Since we never can perceive the psychic experiences of other in any direct fashion, as with physical phenomena, we can only make some kind of a representation of them. There has to be an act of empathy, of understanding, to which the phenomena occur, or we may make sharp comparisons or resort to the use of symbols or fall back on a kind of suggestive handling of the data. Our chief help in all this comes from the patients' own self-descriptions, which can be evoked and tested out in the course of personal conversations (Jaspers). ${ }^{.54}$

Demarcation is not, in relation to, a peculiar definition to philosophical phenomenology but the concept formation in 
the customary sense. Further, description is most importantly stressed to establish the systematic categories, comparisons, demonstration of similarity, and arrangements in series in a Jaspersian sense..$^{50,51}$

By Jaspers, it was suggested that the reorganized methodology that the psychological part of psychopathology should be clearly distinctive from its non-psychological aspects. Further, the study of the subjective phenomena as experienced by patients was separated from the study of other psychological data that was proposed as a new phenomenological trend. In a Jaspersian sense, empathy was considered a diagnostic method to make a distinction between what is understandable and what is not understandable in psychic life. Psychiatric diagnosis is not a "simple question-and-answer interrogation" but a "particular observation," which means that observed findings can depend on a perspective of the assessed tools. Despite the predominance of the operational criteria, including a simple application of the Kraepelinian classification, a proper diagnosis can be made by establishing a therapeutic alliance with the patient through empathic work. Based on the emphasis of Jaspers on empathy, pathological psychic life of the first kind can be comprehended vividly with an exaggeration or diminution of the known phenomena, whereas pathological psychic life of the second kind cannot be comprehended appropriately in this way. ${ }^{7,14,52}$ Hence, as earlier mentioned, the rigorous distinction between explanation and understanding was established to evaluate the psychic phenomenon. Thus, both the opposite extreme poles of Carl Wernicke's dogma that "all mental illnesses are cerebral illnesses" and Sigmund Freud's dogma that "all mental illnesses are personality illnesses" could be criticized in terms of theoretical incompleteness. In a Jaspersian sense, it could be considered that explanation was the only epistemological method of psychiatry in entirely somatic approaches but understanding was the only method in entirely psychic approaches. ${ }^{1,53}$ Moreover, in a Jaspersian sense, the pathological experiences can be conceptualized with a distinction between process (Proze $\beta$ ) and development (Entwicklung) (Table 1). For the psychic pathological experiences, development denotes the maintenance for continuum of motivation, goals, and the meaning in the context of empathic understanding, whereas process denotes the un-understandable phenomena that disparate factors intervene basic psychic structure. Jaspers proposed a distinction between static understanding and genetic understanding. In the Jaspersian view, static understanding denoted "grasping the particular psychic qualities and states as they were experienced," whereas genetic understanding "grasps the emergence of one psychic state out of another." ${ }^{\text {15-23,30,45-48 }}$

\section{KARL JASPERS' GENERAL PSYCHOPATHOLOGY: ITS RELATIONSHIP WITH KOREAN PSYCHIATRY AND ITS IMPLICATIONS FOR CURRENT PSYCHIATRY}

After the introduction of modern Western psychiatry into Korea in late 19th century, it is presumed that Jaspers' GP had been initially introduced to Korean psychiatry. Further, it is known that Jaspers' GP might be used as a reference book by the professors and members in department of neuropsychiatry at Keijo Imperial University during the period of Japanese colonial rule in Korea (1910-1945). ${ }^{55}$ Dr. Charles Inglis McLaren (1882-1957), a medical missionary from the Australian Presbyterian Church, gave the lectures for psychiatry and neurology at Severance Union Medical School from 1913 to 1938. Alluding to Jaspers' criticism on brain mythology, McLaren's view was that human beings should be regarded as the "bodymind continuum within an active materio-spiritual cosmos." McLaren proposed a humanitarian approach in psychiatry through spirit medicine under the influences of Christianity. ${ }^{56-59}$ Hence, there is a possibility that a Jaspersian approach may be partially related to the theoretical background for McLaren's humanitarian approach. Dr. Rhee Dong-Shick (19202014) has presented Tao psychotherapy, which is a cohesive form of the Eastern Tao (道) and the substance of Western psychotherapy to overcome the hindrance of cultural factors on psychotherapeutic practice in Korea. ${ }^{60-63}$ A sentence of the $G P$ that "psychotherapy is the name given to all those methods of treatment that affect both psyche and body by measures which proceed via the psyche (Jaspers)" ${ }^{\prime 64}$ has been quoted in a preface in Dr. Rhee's book, Introduction to Tao Psychotherapy. ${ }^{65}$ Although a partial sharing of the theoretical backgrounds of Jaspersian phenomenological psychopathology with Tao psychotherapy cannot be explained simply, its potential relationship cannot be excluded. Moreover, further studies are required on the subject. In 2011, in order to reduce stigma on schizophrenia, the Korean term for schizophrenia has been changed from jungshinbunyeolbyung (精神分裂病; split-mind disorder) to johyeonbyung (調絃病; attunement disorder) ${ }^{66-68}$ Most of all, "attunement disorder," the English translation of johyeonbyung, denotes the phenomenological Gestalt during schizophrenic experiences. Initially, "attunement" is the English translation of German philosophical terms Befindichkeit or Stimmung. In Martin Heidegger's definition, Befindichkeit denotes the emotion that Dasein feels in response to the world with its complex network of meaning. Moreover, selfexperience (ipseity) is proposed from a Jaspersian sense and corresponds to Befindichkeit in the phenomenological-anthropological tradition for psychopathology. While a phenom- 
enological-anthropological understanding has no direct influence on reducing the stigma of schizophrenia, an assumption can be made that a Jaspersian sense partly contributes to the concept of attunement disorder. ${ }^{69}$ Thus, it is speculated that the Jaspersian sense can be potentially and partially related to the humanitarian approaches, including Dr. McLaren's spirit medicine, Dr. Rhee's Tao psychotherapy, and the renaming of the Korean term for schizophrenia in Korean psychiatry.

In terms of the diagnostic scheme for psychiatric disorders, with the fall of psychoanalytic approach in 1980s, a Kraepelinian nosological model has been inherited by the DSM-III, DSM-IV, and DSM-5. The Kraepelinian empirical trend aimed at conceptual fitting all the psychiatric disorders to the RRUS paradigm including the general paresis model of the insane (neurosyphilis). However, Jaspers was against a Kraepelian biological absolutism. As shown in Table 1, Jaspers divided the psychiatric disorders into three groups in the GP. Group I denotes the "known somatic illness with psychic disturbances," which is consistent with Kraepelin's idealism and included cerebral illnesses, systemic diseases with symptomatic psychoses, and poisons. On the contrary, group III denotes the "abnormal reactions, neurosis, neurotic syndromes, as well as, abnormal personalities and their developments," which are seen as a variation of normality rather than a medical model. Group II denotes the "major psychoses," which is located between group I and group III and includes genuine epilepsy, schizophrenia, and manic-depressive illness. Though group II is distinguished from normality variation, its boundaries are not clearly separated. Hence, a Jaspersian sense has a potential virtue to replenish the failure to the heterogeneous nature of psychiatric disorders in a Kraepelinian sense. ${ }^{1,8-11}$ In Jaspers' view, the classification of mental disorders was regarded as simply "drawing the line where none exists," and each psychiatric diagnosis had only "provisional value." However, according to disease essentialism, current psychiatric diagnostic systems including the DSM have been defined in the categorical classification. ${ }^{70}$ The disease essentialism paradigm has assumed that observable symptoms or signs can be defined precisely and psychiatric diagnoses can be identified unambiguously. Furthermore, from the viewpoint of the categorical classification approach, each psychiatric diagnosis has been regarded as equivalent to the underlying biological process. Hence, disease essentialism has been similar to the medical disease entities that are conceptualized with empirical methods and defined based on their biological essences. However, the biological essences have not been revealed in most of psychiatric diseases. Mental disorders cannot be classified based on natural kinds of boundaries. Boundlessness can be a distinctive feature of psychiatric nosology and taxonomy, but not the other medicines. Despite the rise of neo-Kraepelinian ap- proaches including DSM, according to Wittgenstein's analogy with language games, psychiatric diagnosis can be compared to a family of cases that are associated flexibly and intricately by their family resemblance but not by their essence or by a single characteristic or process. ${ }^{37,71,72}$ Hence, according to Sass and Vople ${ }^{70}$ the "shortcomings of modern psychiatric diagnostic classification" were suggested as follows: "reductionism in conceptualization of psychopathology and its assessment," "inflation of diagnostic categories," "consensus-politics and scientific imperialism," "rarification of psychopathological differentiations," "danger of reification of verbalized syndromes based on conventions," "abandoning crucial psychopathological concepts including neurosis, psychosis and endogenous depression," "abandoning conceptual history and psychopathological traditions," "abandoning psychodynamic and psychostructural factors," "disregarding aspects of subjective experience and biography," "lack of predictive validity, including therapeutic response and course," "restriction to observable behavior," and "horizontalization of clinical diagnosis by the concept of comorbidity." Thus, in a Jaspersian view, a phenomenological approach has been proposed as a significant method for complementing the current categorical classification. Based on an appreciation of the nature of consciousness or subjectivity, psychiatric symptoms or signs can be adequately understood from the perspective of phenomenological pathology. Also, it is speculated that Jaspers' hierarchical principle, which has been proposed as three distinctively defined groups of diseases, can set off the "shortcomings of modern psychiatric diagnostic classification." Moreover, the viewpoint of the Research Domain Criteria (RDoC) on psychiatric disorders has been estimated as a similar scheme to Wernicke's view that "cerebral illnesses in the sense that they can be wholly comprehended in terms of cerebral processes." Hence, from the viewpoint of the RDoC, it cannot exclude a possibility that explanation would be overestimated but understanding would be underestimated. ${ }^{1,56}$ In addition, the establishment of methodology and methodological criticism in psychopathology as well as the new introduction of phenomenology into psychopathology were the valuable achievements of Jaspers' $G P$. In a Jaspersian sense, acceptance of open questions for knowledge and awareness of one's own limits are needed to establish the "hermeneutic circle." Hence, it has been suggested that current molecular psychiatry has a chance to widen its perspectives to see its own biological borders and to overcome its own solipsism, frustration, and lack of orientation with the help of the Jaspersian view. ${ }^{73}$

\section{CONCLUSION}

Under the influences of a Husserlian and a Ditheyan sense, 
in Jaspers' GP, explanation and understanding have been suggested as a proper epistemological tool for estimating the psychical phenomenon. Further, a distinction between process and development has been proposed to describe the pathological experiences. Jaspers' GP has contributed to not only the introduction of phenomenological trend into psychopathology but also the proposal for the comprehensive and integrated approaches to overcome the confusion of various academic backgrounds in German psychiatry before and after World War I. Hence, the humanitarian approach in Korean psychiatry has shared the common theoretical background with a Jaspersian sense. Whereas a Kraepelinian biological absolutism has failed to comprehend the heterogeneous natures of psychiatric disorders and the RDoC has underestimated understanding, the Jaspersian sense still enables to help widen viewpoints in terms of psychiatric taxonomy. Furthermore, the solipsism, frustration, and lack of orientation of current molecular psychiatry may be helped by the Jaspersian sense.

\section{Acknowledgments}

This study was supported Jisan Cultural Psychiatry Research Fund (2016) of the Korean Foundation of Neuropsychiatry Research.

\section{REFERENCES}

1. de Leon J. DSM-5 and the research domain criteria: 100 years after Jaspers' General psychopathology. Am J Psychiatry 2014;171:492-494.

2. Maj M. Mental disorders as "brain diseases" and Jaspers' legacy. World Psychiatry 2013;12:1-3.

3. Fusa-Poli P. One century of Allgemeine Psychopathologie (1913 to 2013) by Karl Jaspers. Schizophr Bull 2013;39:268-269.

4. Bertelsen A. Karl Jaspers (1883-1969) and the centenary of 'Allgemeine Psychopathologie.' Acta Psychiatr Scand 2013;127:438-439.

5. Kupfer D, Regier D. Neuroscience, clinical evidence, and the future of psychiatric classification in DSM-5. Am J Psychiatry 2011;168:672-674.

6. Berrios GE. Descriptive psychopathology: conceptual and historical aspects. Psychol Med 1984;14:303-313.

7. Ghaemi SN. Understanding Mood Disorders: Karl Jaspers' Biological Existentialism. In: Stanghellini G, Fuchs T, Editors. One Century of Karl Jaspers' General Psychopathology. Oxford: Oxford University Press, 2013, p.245-257.

8. Engstrom EJ, Kendler KS. Emil Kraepelin: icon and reality. Am J Psychiatry 2015;172:1190-1196.

9. Kendler KS, Engrom EJ. Criticisms of Kraepelin's psychiatric nosology: 1896-1927. Am J Psychiatry 2018;175:316-326.

10. Ghaemi SN. Nosologomania: DSM \& Karl Jaspers' critique of Kraepelin. Philos Ethics Humanit Med 2009;4:10.

11. Parnas J. DSM-IV and the Founding Prototype of Schizophrenia: Are We Regressing to a Pre-Kraepelinian Nosology? In: Kendler K, Parnas J, Editors. Philosophical Issues in Psychiatry II: Nosology. Oxford: Oxford University Press, 2012, p.237-259.

12. Shorter E. The History of DSM. In: Paris J, Phillips J, Editors. Making the DSM-5. New York: Springer, 2013, p. 3-20.

13. Andreasen NC. DSM and the death of phenomenology in America: an example of unintended consequences. Schizophr Bull 2007;33:108-112.

14. Havens L. Karl Jaspers and American psychiatry. Am J Psychiatry 1967; 124:104-108.

15. Yang BY, Moon HS. Karl Jaspers and general psychopathology. Korean J Psychopathol 1992;1:12-21.
16. Yang BY, Hong SK. Psychopathology of delusion: the phenomenological approach of Karl Jaspers. Korean J Psychopathol 1996;5:15-26.

17. Yang BY, Hur YS. Karl Jaspers and psychopathology. Korean J Psychopathol 2002;11:3-11.

18. Yang BY, Kim YS. The conceptual history of delusion. Korean J Psychopathol 2008;16, 17:3-6.

19. Yang BY, Lee K. History of psychopathology: from ancient to 19th century. Korean J Psychopathol 2014;22:3-10.

20. Yang BY, Hwang HS. The differentiation and integration of mind and body. Korean J Psychosom Med 2000;8:110-121.

21. Min HW, Hong SK, Jung SA, Lee JH, Yang BH. A preliminary study for illuminating formal ways of pathological language behavior. J Korean Neuropsychiatr Assoc 2001;40:569-580.

22. Lee S. Recent trends in Germen psychiatry (I). J Korean Neuropsychiatr Assoc 1973;12:153-161.

23. Lee S. Recent trends in Germen psychiatry (II). J Korean Neuropsychiatr Assoc 1973;12:225-234.

24. Jaspers K. Philosphische Autobiographie. Munchen: Serie Piper; 1977.

25. Saner H. Karl Jaspers in Selbstzeugnissen und Bilddokumenten. Hamburg: Reibek; 1979.

26. Jablensky A. Karl Jaspers: psychiatrist, philosopher, humanist. Schizophr Bull 2013;39:239-241.

27. Schwartz MA, Moskalewicz M, Wiggins OP. Karl Jaspers: the icon of modern psychiatry. Is J Psychiatry 2017;54:4-8.

28. Ghaemi SN. Existence and pluralism: the rediscovery of Karl Jaspers. Psychopathology 2007;40:75-82.

29. Fuchs T, Herpertz S. The centennial of Karl Jaspers' general psychopathology. Psychopathology 2013;46:279-280.

30. Jasper K. The phenomenological approach in psychopathology. Br J Psychiatry 1968;114:1313-1323.

31. Mundt C. The History of Psychiatry in Heidelberg. In: Spitzer M, Uehlein F, Schwartz MA, Mundt C, Editors. Phenomenology, Language and Schizophrenia. New York: Springer-Verlag, 1992, p.16-31.

32. Janzarik W. 100 years of Heidelberg psychiatry. Hist Psychiatry 1992; 3:5-27.

33. Janzarik W. Jaspers, Kurt Schneider and the Heidelberg school of psychiatry. Hist Psychiatry 1998;9:241-252.

34. Yasyuki M. Jaspers' Philosophy from Psychiatry to 'Illumination of Self. In: Yasyuki M, Editor. Jaspers from Psychiatry to Philosophy: Humanistic Approaches. Tokyo: Showa Publishers, 2012, p.90-96.

35. Beauchesne H. Historie de la Psychopathologie. Paris: Presses Universitaires de France; 1986. Ohara K, Takauchi, Translators. First Phenomenological Approach in Psychiatry. History of Psychopathology. Tokyo: Seiwa Shoten Publishers, 2014, p.155-207.

36. Heerlein A, Cornaglia C. The Reception of Jaspers' General Psychopathology Outside of Europe. In: Fuchs T, Breyer T, Mundt C, Editors. Karl Jaspers' Philosophy and Psychopathology. New York: Springer, 2013, p. 61-74.

37. Song JY. Development of Psychopathology. In: Song JY, Editor. Introduction to Psychopathology. Seoul: Jipmoondang Publishing Co., 2012, p.20-31.

38. Hoenig J. Karl Jaspers' general psychopathology: the history of the English translation. Hist Psychiatry 2004;15:233-236.

39. Rhi BY. General Psychopathology. In: Lee TH, Editor. Great Essay of Contemporary Thinkers. Seoul: Taegeuk Publishing Co., 1974, p.321-379.

40. Jaspers K. Allgemeine Psychopathologie, Neunte Auflage. Berlin: Springer Verlag; 1973.

41. Kumazaki T. The theoretical root of Karl Jaspers' General Psychopathology. Part I: Reconsidering the influence of phenomenology and hermeneutics. Hist Psychiatry 2013; 24: 212-226.

42. Kumazaki T. The theoretical root of Karl Jaspers' General Psychopathology. Part II: The influence of Max Weber. Hist Psychiatry 2013; 24 : 259-273.

43. Leoni F. Jaspers in His Time. In: Stanghellini G, Fuchs T, Editors. One Century of Karl Jaspers' General Psychopathology. Oxford: Oxford Uni- 
versity Press, 2013, p.3-15.

44. Paek MJ, Kang UG. Phenomenological psychopathology. J Korean Neuropsychiatr Assoc 2011;50:97-115.

45. Park SC. The Goldwater rule from the perspective of phenomenological psychopathology. Psychiatry Investig 2018;15:102-103.

46. Parnas J, Sass LA, Zahavi D. Rediscovering psychopathology: the epistemology and phenomenology of the psychiatric object. Schizophr Bull 2013;39:270-277.

47. Ebmeier K. Explaining and understanding in psychopathology. Br J Psychiatry 1987;151:800-804.

48. Berrios GE. Phenomenology and psychopathology: was there ever a relationship? Compr Psychiatry 1993;34:213-220.

49. Jaspers K. Allgemeine Psychopathologie. Berlin: Springer Verlag; 1959. Hoenig J, Hamilton MW, Translators. Appendix. General Psychopathology. Chicago: The University of Chicago Press, 1968, p.849.

50. Spiegelberg H. Phenomenology in Psychopathology and Psychiatry. In: Spiegelberg H, Editor. Phenomenology in Psychology and Psychiatry. Evanston: Northwestern University Press, 1972, p.91-124.

51. Spiegelberg H. Karl Jaspers (1883-1969) Introducing Phenomenology into Psychopathology. In: Spiegelberg H, Editor. Phenomenology in Psychology and Psychiatry. Evanston: Northwestern University Press, 1972, p.173-191.

52. Havens LL. Participant Observation. Northvale, NJ: Jason Aronson; 1983.

53. Franzek E. Influence of Carl Wernicke on Karl Leonhard's nosology. Psychopathology 1990;23:277-281.

54. Jaspers K. Allgemeine Psychopathologie. Berlin: Springer Verlag; 1959. Hoenig J, Hamilton MW, Translators. Introduction. General Psychopathology. Chicago: The University of Chicago Press, 1968, p.55.

55. Rhi BY. Hundred years' psychiatry in Korea (1899-1999). Korean J Med Hist 1999;8:157-168.

56. Chung W, Lee N, Rhi BY. The introduction of Western psychiatry into Korea (II): psychiatric education in Korea during the forced Japanese annexation of Korea (1910-1945). Korean J Med Hist 2000;15:157-187.

57. Yeo IS. Dr. Charles Inglis McLaren (1882-1957): a psychiatrist who treated the Korean soul. Yonsei Med J 2018;59:172-175.

58. Min SK. Professor Charles I. McLaren, MD (1): his life and medical philosophy. J Korean Neuropsychiatr Assoc 2011;50:172-186.

59. Min SK. Professor McLaren (2): his theories of psychiatry. J Korean Neuropsychiatr Assoc 2012;51:25-35.
60. Rhee D. The tao, psychoanalysis and existential thought. Psychother Psychosom 1990;53:21-27.

61. Kang SH. Training and development of psychotherapy in Korea. Psychother Psychosom 1990;53:46-49.

62. Im JY. A study of the discussions on psychiatry of Korea in the 1960s and 1970s: from mental hygiene to modern psychiatry. Korean J Med Hist 2017;26:181-214.

63. Lee MS, Park YC, Park SC. South Korea. In: Bhugra D, Tse S, Ng R, Takei N, Editors. Routledge Handbook of Psychiatry in Asia. New York: Routledge, 2015, p.183-195.

64. Jaspers K. Allgemeine Psychopathologie. Berlin: Springer Verlag; 1959. Hoenig J, Hamilton MW, Translators. Appendix. General Psychopathology. Chicago: The University of Chicago Press, 1968, p.834.

65. Rhee D. What Is Psychotherapy? Introduction to Taopsychotherapy: Beyond Freud and Yung. Seoul: Hangangsu Publishers, 2008, p.44.

66. Lee YS, Kim JJ, Kwon JS. Renaming schizophrenia in South Korea. Lancet 2013;382:683-684

67. Lee YS, Park IH, Park SC, Kim JJ, Kwon JS. Johyeonbyung (attunement disorder): Renaming mind splitting disorder as a way to reduce stigma of patients with schizophrenia in Korea. Asian J Psychiatry 2014;8:118120.

68. Cho JW, Jang EY, Woo HJ, Park YC, Kim SH, Hong KS, et al. Effects of renaming schizophrenia in Korea: From "split-mind disorder" to "attunement disorder." Psychiatry Investig 2018;15:656-662.

69. Jeong SH, Son JW, Kim YS. Understanding of "attunement disorder" from phenomenological-anthropological perspective: Inquiry into the use of the term "attunement disorder" in psychiatric literature. J Korean Neuropsychiatr Assoc 2013;52:279-291.

70. Rosenman S, Nasti J. Psychiatric diagnoses are not mental process: Wittgenstein on conceptual confusion. Aust N Z J Psychiatry 2012;46:10461052.

71. Mckinejad K, Sharifi V. Wittgenstein's philosophy and a dimensional approach to the classification of mental disorder: a preliminary scheme. Psychopathology 2006;39:126-129.

72. Sass H, Volpe U. Karl Jaspers' Hierarchical Principle and Current Psychiatric Classification. In: Stanghellini G, Fuchs T, Editors. One Century of Karl Jaspers' General Psychopathology. Oxford: Oxford University Press, 2013, p.185-207.

73. Thome J. Centenary of Karl Jaspers's general psychopathology: implication for molecular psychiatry. J Mol Psychiatry 2014;2:3. 